\title{
The Formation of Citizenship as a Necessary Condition for Effective Socio-Economic Development of Society
}

\author{
Vakifa Gilmanovna Khayrullina, \\ Docent, Professor, Institute of Economics, Finance and Business, Bashkir State University \\ E-mail: vakif47@mail.ru
}

Elena Rubinovna Gilyazetdinova

Assistant, Institute of Economics, Finance and Busines, Bashkir State University Email: gilyazetdinova.e@mail.ru

\section{Doi:10.5901/mjss.2015.v6n2s4p89}

\section{Abstract}

The article is devoted to the role of culture in shaping the younger generation citizens, creators of socially important benefits. The aim of this article is consideration of the functional role of the education system in social-economic development of the society on the basis of system approach and laws of organization. From these scientific provisions the necessity follows about distinct formulation in the law about education of the strategic aim of the development of the system of education as the responsible institute for formation of rising generation by the competent labour resources for the economy of its state, citizensconstructors of socially valuable spiritual and materials goods.

Keywords: culture, state, education system, citizen, human.

\section{Introduction}

The aim of this article is consideration of the functional role of the education system in social-economic development of the society on the basis of system approach and laws of organization.

The accumulated volume of new scientific knowledge, especially for the last two centuries evidences about necessity of not only uninterrupted addition of the individual branches of applied sciences by them, but also the review of the social-economic development paradigm. On the assumption of this position, let's consider the following theses.

The first thesis: the system of education is state institute responsible for entering of the new generation into culture, and it means for formation of the labour citizens, going on the change of generation, who reached the pension age.

The second thesis: outlook of the schoolchildren - spiritual-intellectual constituent of their personality, determining the level of their citizenship, creative behaviour and culture of consumption behaviour.

The third thesis: only owing to the upbringing of the valuable relation to the labour, organization of the active participation of the rising generation in the culture formation process it is possible to improve the structure of labour resources of any state. Among the factors of production only labour resources possess creative ability. According to just expression of P. Drucker: "Only human resources are able to produce economic results... All other resources are subjected to the laws of mechanic, they can be used for better, but their outcome never would be bigger than the amount of inputs" [stated according to: 1, p. 9].

According to the law of dialectics, "Quantitative changes in the system of any nature are accompanied by the qualitative changes". In this contest the question arises about how these changes take place either in the form of selforganization, or they are organized and managed processes?

The necessity of answering on these issues of life caused the appearance of such sciences as theory of organization, theory of systems, cybernetics, theory of information and synergetics. All they are directed on detection of the regularities of appearance, functioning and development of complex systems of natural and social origins.

Taking the generally accepted laws and principles as the starting point, we'll consider the role of education system that is subsystem of the state. At that we understand the state as the system of higher order, as supraorganizmal phenomenon, provided with the force of power for supporting order in the society. The citizens are considered as indivisible elements of the system, which form its structural units (i.e. components as family, enterprises and organization). 


\section{Research Methodology and Findings}

For understanding the character of public relations, we'll consider the regularities of human formation as a citizen of his state.

According to the definition, stated in the dictionary of D.N. Ushakov, a citizen is a person that belongs to the population of any state, which uses all rights provided by the laws of this state and executing all obligations, established by the laws of this state; national of any state. It is a conscious member of the society and human that subdues his own personal interests to the public ones [2, p. 164]. The expression of poet Nekrasov is generally known: "You may not to be a poet, but you must be a citizen".

The citizen is in wide sense the personality, provided with civil rights and obligations that successfully masters and uses civil values. They include the high degree of individual self-organization and self-organization as a part of society; personal responsibility for individual choice and actions, state and development of the society; civil patriotism; active participation in the civil activity; education and critical thinking; tolerance, indulgence and respect to other opinions, judgements, views and self-respect, ability to defend own point of view; ability to dialogical forms of social interaction and spiritual contact; respect to the past, devotion to its best samples and values; physical and moral health; intolerance to extremism; democracy and humanism as a principle of social behaviour and thought; industriousness; compassion to those one, who endures physical and moral tortures. the slave, conformist, dictator, bureaucrat, cynic, dogmatic person, reactionary, extremist, passive resident, boor, orthodox, xenophobe, Pharisee, social dependant, criminal, flatterer and sycophant serve as antipodes of the citizen in the social world most frequently [3, p. 58].

On the assumption of the above stated the importance of notion "citizenship" results. We understand the citizenship as high level of personality socialization, group of persons, their qualitative state, which is displayed in the high consciousness usage of their right and freedoms, is closely connected with personal and collective responsibility and necessity to execute their obligations in the interests of the society [3, p. 61].

Within the theses considered it should be noted that a human at the birth represents only biological creature, potentially gifted with the deposits of citizenship. The formation of a human as a deserved citizen of own state, corresponding to the social orientation of the market mechanism of the economy is long-term process.

Formation of the rising generation as high-cultural citizens is connected with transformation of the mentality of the adult population in relation to the norms of socially oriented market economy. This process has implicit character and is displayed in the society through the actions of concrete people, i.e. through their behaviour in the daily life. The effectiveness of this process in many respects depends on the conducted social-economical policy of state, i.e. educational one.

The recognition and accounting of this regularity to representatives of state bodies is displayed in the form of improvement of social institutes. Thus on the stage of formation the young science "organization culture" is. In the higher educational establishments of our state on the basis of determination of culture, the state educational standard is accepted. The content of this document aims the activity of educational institutions of all levels on formation and development of the generally cultural and professional competences in rising generation.

In this context the necessity of culture essence exposure appears.

In the opinion of many scientists, from different definitions of culture the most system, logically substantiated and universal is determination, given by Pitirim Sorokin. He defines the culture as "aggregate of knowledge, values and standards, which the associated persons possess, and aggregate of bearers, which objectify, socialize and disclose these values" [stated according to: 4 , p. 339].

It follows from this definition that the following things are sense forming in this notion: constructively active human labour subject; hierarchy of the society - form and condition of the human life activity; spiritual and material goods (products) of the creative human activity (labour subject) and society (family and hierarchy of the professional enterprises, organizations, state institutes and structures of power). At that the compulsory condition for understanding the culture is the necessity of its understanding as: the result of life activity of the generations, ideal senses, values, status provision to them, behavioural standards for all members of this society as the "content" of the internal world of each person that is revealed in the society in the form and constructive and descriptive activity as energetic information resource, materialized in the process of labour in socially valuable goods.

It should be noted that the basic object of organizational culture study is commercial and public organizations. So this discipline emphasizes its attention on the research and study of the regularities of intercourse, business communication, social responsibility of all business participants and state service before the citizens of own state.

Thus, on the assumption of the stated scientific provisions it is possible to make a conclusion that: 1) the state and especially the general education system as its structural component that forms outlook of rising generation about social 
norms of life, is "social organism", - a bearer, keeper and creator of organizational culture; 2) organizational culture is the direct factor of stable social-economic development of the economic subjects of all levels. For detection of the essence of this conclusion we'll continue the system analysis of the culture in wider sense.

It is generally accepted that the culture is divided into ideal and material one. As many scientists consider, these two subsystems of culture are in the unity and can be understood only at their consideration in interaction of a human and society in the dynamics (part-present-future). "At that in relation to the culture the ideal constituent plays the leading role, and material one has servicing, and additional meaning, and provides the material embodiment and objectification of the spirit" [4, p. 341]. Therefore, the material components of culture can be considered to be bearers of the spiritual culture.

The ideal culture represents the structure, consisting of the general human values (as invariant constituent) and standards of current life (i.e. changeable part).

Generally accepted values serve as foundation of formation and development of the human internal world, beginning from the children's age.

This important scientific position increases actuality of the disclosure of the culture part in formation of the individual by the personality and role of the society for implementation in the culture. Such approach allows considering the state as cultural space, filled with the social standards, reference points, perceptions, and representations, which the citizens are guided by; as the space of entering of each new generation (changeable outgoing generation) in the content of its labour resources, providing the connection of generation upon the condition of understanding its sense.

For giving the bigger clearness to the stated positions, we'll consider the role of culture in the formation of an individual as personality (in its "humanizing"). Thus, the new-born human can be considered inspired biological creature, as synthesis of the biological and potentially laid emotional-volitional one. Emotional-volitional constituent of the new-born serves the precondition for its "culturing", i.e. spiritual-intellectual development further (psychic constituent of a human). Spiritual-intellectual development of the child (i.e. formation of psychic component of a human) begins upon the extent of perception of the basic social standards by them.

From the above-stated provisions, it comes out that the human perceiving culture in childish age, becomes personality, upon the formation of personality - the creator of the society culture. The state is spatially-temporary condition of the storage and multiplication of the culture for entering of each new generation into it.

For applied exposure of the essence of this provision we'll consider the peculiarities of entering of the rising generation of Russia in 90s years of the past century into the culture. In those years, children in the age of active socialization turned out to be in energetic information space of radical changes of the social-economic life standards. The standards of regulation of political, economic, and social life, based on the communistic ideology was changed. The state stopped to be organization that performs its function, in accordance with certain ideology.

Paying attention of the public on the value of ideology as organizing and disorganizing forces of the society, the scientist Yu.G. Volkov marks: "The declared deideologization of the Russian society after August revolution (1991) led to natural to social chaos. The functioning social areas and structures of the society acquired the imbalanced character, so that the ideological structure of the soviet society was destructed, and new ideological structure was not created. As the deideologization principle, i.e. no one ideology, full freedom of actions. ... The stagnation took place, and then their decomposition (in the form of criminalization and corruption) of the state and public structures of the Russian society. ... Its dehumanization and ... its transformation into individuals without historical memory and tribeless took place, i.e. native land, that indeed bears further degradation and self-destruction to the youth. ... The Russian higher educational establishments became the suppliers of the staff for the developed countries of capitalism" [6, p. 39].

As a result of these processes the liquidation of Komsomol, pioneer, and October organizations intended to form the senses of patriotism and culture of construction in the rising generation within the frameworks of school education.

Finally, the adult citizens in our country, who get accustomed to guide themselves with life principles "he that will not work shall not eat", "a man is famous for its deeds", and "from each according to his ability, to each according to his need" found themselves in the liberal society of individualism with principle "every man for himself", and "everything goes, it is doesn't contradict to the law" [7, p. 16].

These revolutionary processes in the standards of the public life at the absence of the new ones caused the deformation in the outlook structure in the part of population, suppression of the valuable relation to the labour in it. As a result of such changes the aspiration to the rapid enrichment enhanced not owing at the expense of labour profits. It caused the intensive growth of economic and criminal delinquency on the background of which the quantity of homeless children and drug-addicts, socially unprotected layers of the population increased. At the same time these negative phenomena aggravated civil war on the North Caucasus, slave trade, terroristic act, multi-month delay of the wage of the teachers and physicians. The army was demoralized.

At these conditions the initiative citizens-entrepreneurs began to establish own business. However, their economic 
activity was executed and at the presence of the civilized regulating norm, or at very incomplete standards, including the standards of taxation. Many legislative standards contradict each other.

As the result of privatization "changing hands", the basic production funds of former state enterprises physically and morally become obsolete. Amortization deductions instead of the renewals of the basic capital of enterprises used as floating assets. The enterprises of military-industrial complex (MIC) worsened. The majority of enterprises of light industry were transformed into shopping and entertainment center [8, p. 10-11].

In these years the intensified outflow of the financial capital, "brains" abroad has begun. The substantial part of the national economy was controlled by oligarchic and criminal structures. The financial system of the country was in full dependence from the external borrowings. The unemployment reached up to $9 \mathrm{mln}$ people.

Thus, the rising generation of 90 s turned out to be in the space of culture crisis, accompanied by the sharp drop in the system of life values of the labour rating. The core element of the public consciousness, which only labour is the source of life provision (profit) of a human, was diffused by the advertisement financial pyramids. The means of mass media (MM) filled the information space of the ideas: "the source of profits - "rent-seeker". The space of life activity of the rising generation was filled with energetic information, formed the stereotype of behaviour "achieve the success by any means, consumes and enjoy".

This led to default of 1998. As a result many enterprises were ruined, and the poverty of population grew even more. In 1999 the real profits of the citizens made only 40\% from the level of 1991, and pensions - even less. Almost the third of population has the profits lower the living minimum $[9, p .7]$.

As a result of such radical changes in the scale of our national economy the level of labour productivity and technological culture dropped substantially, we - the citizens of Russia began to live predominantly not at the expense of labour, but at owing to the export of non-renewable natural resources, belonging not only to the present, but to the future generations too.

The present young part of labour resources of our state represents the generation of $90 \mathrm{~s}$, which outlook bases formed in the crisis cultural space. Thus, the studies of the valuable orientations of present senior pupils showed that "according to rating of the significance materially provided life, not supported by own labour contribution, takes the top place for majority that tells about low level of moral culture and inability to execute free choice an bear responsibility for it" $[10$, p. 5].

It should be noted that beginning from 1999 owing to the efforts of new management in our state, the huge word on making constitutional order and strengthening of the state institutes is conducted, i.e. on formation of the socially responsible state power. As V.V. Putin marked in his speech on February 8, in 2008: "Today we already completely restored the social-economic development level lost for 90s years. Real profits of the citizens exceeded pre-reform indicators... The positive changes in education, science and health protection take place. The state again appealed to the problems of national culture" [9, p. 10]. On this meeting of the State Council of 2008 the long-term strategy of Russia development up to 2020 year "the strategy of innovation development of the country that relies on one of our main competitive advantages - on implementation of the human potential, on the most effective application of knowledge and abilities of people for the constant improvement of the technologies, economic results, and society activity on the whole. ... From motivation to innovation behaviour of the citizens and from the return that is brought by the labour of each human, the future of Russia will depend" [9, p. 12].

Thus, the reforms of 90s of the past century once more in the practice showed the role of culture in the human life activity and society and role of ideology as a strategic organizing force, a strategic aim of culture and organization.

Analysis of this period convinces in the appropriateness of the following positions.

1. The culture is necessary for constructive organization, as all recognized the position: "From the moment of origin of life on our planet there were then and are not only two types of organization: functional and military ones. The first type can be otherwise called the organization of construction, and the second one organization of destruction [11].

2. Organization of construction - these are processes of:

recognition of the nature and society for understanding of their laws, i.e. formation of the ideal culture;

- materialization of the ideal culture (conceptions, knowledge) in socially valuable goods, i.e. formation of socially valuable material culture.

Therefore, we understand the material culture as the subjects and things, if they have socially valuable source. Such subjects and things are the bearers of spiritual culture (material reflection of the state of a man-creator internal world).

3. Organization of the construction is the process of synthesis of structural constituents of the system, which sense forming structural elements are cultural human - personality. Such person is a bearer of ideal culture, 
created for it, and supporting on them, builds its activity purposefully, giving it the socially valuable sense. In practice organization of construction should be expressed through the notion of "labour".

4. Construction organization is the process of formation and development of the personality, i.e. culturing the individual (new-born); it is the appropriate process of organization of child entering into the culture, and its socialization. The aim of the organization process is formation of the constructor's structure and provision of the personality with constructive ability. In practice the constructive ability of a human should be expressed through the notion "labour capacity", and labour capable person - labour subject, and the process of labour capable behaviour formation - upbringing and education.

5. The parent and family members, relative of family members, the closest society (neighbours, yard with child ground) and state institutes - pre-schools and institutions of general secondary, primary professional, secondary professional and higher professional education are the subjects of child upbringing as a labour capable citizen (culture constructor). In this process mass media and other social institutes play huge role.

All enlisted subject represent the citizens of the Russian Federation (RF), who reside on the certain administrativeterritorial unit - region. Each region of RF is:

- single cultural space, filled with energetic information about social norms, regulating interrelations of the citizens of this administrative-territorial unit;

- the social system that includes in it citizens of different age, different level of labour capacity and constructive activity;

- the space, on which the quality of life of generation especially in port-labour capable age depends (upon other equal conditions) on the labour capacity level of the generation that comes for its change.

Implementation into the public conscious of such understanding of succession of generations will allow increasing the responsibility of managers of all levels of state power, public organizations, institutions of the education system for formation of the rising generation as labour capable, for creation of the cultural environment of children's upbringing.

In this context it is necessary to pay attention on the contradiction between economy, as a mechanism of production of socially valuable goods, and all increasing demand of the humans at resource restriction. This is the reason why the contradiction arises and the society without social institutes comes to the state of war against all and decomposition. This explains the meaning of the state as a political institute, provided with the legislative, executive and judicial power for organization and control of life activity for all the citizens [12, p. 127].

Thus paying attention to the role of culture in the social-economic development of the society, the role of education as a system of upbringing and education of economy labour resources, and role of distinctly designated social-economic policy of the state as the basic organized instruments of the constructive human and society activity and increase of its effectiveness, Douglas North wrote: "... But how do people come to understanding of the people around? The explanations created by them represent the mental constructions, which come out of the experience of both modern and historical one. The education of a human is something more than accumulation of the individual experience during the life of an individual; it is also the accumulated experience of previous generations. The education of whole society, embodied in language, in the human memory and sign systems, including believes, myths, behavioral means and production of different things, i.e. culture of the society. The culture not only determines functioning of the society in some moment of time, but also laying restrictions on the players, promote to the process of changes in time. ... Understanding is the necessary previous condition that is missed by the economists, who hurry to model the economic growth and changes. We still are far from full understanding of these processes" [stated according to: 13, p. 59].

\section{Concluding Remarks}

Actualizing this problem for our state, the authors of the article: "Institutes: from borrowing to growing (experience of the Russian reforms and possibilities of cultivation of institutional changes)" justly marks: "The analysis of the Russian transformations, which take place since the end of 1980s, evidences about that the difficulties of positive institutional changes in many respects is caused by shallow understanding of the regularities or logics of similar changes, latent persuasion of the reformers in that it is important to write and accept the good laws, and life will be spontaneously changed for better in accordance with their outlines. Meanwhile, the success and misfortunes of our reforms namely confirms that the necessary institutional changes requires systematic efforts and expenditures within enough long periods of time on the basis of thought and flexibly corrected programmes in accordance with environment. At the absence of long-term policy the planned changes either don't take place (sloughed), or perverted, or delayed and accompanied by high losses and expenses" [stated according to: 14, p. 7].

From these scientific provisions the necessity follows about distinct formulation in the law about education of the 
strategic aim of the development of the system of education as the responsible institute for formation of rising generation by the competent labour resources for the economy of its state, citizens-constructors of socially valuable spiritual and materials goods.

\section{References}

About strategy of the development of Russia up to 2000. The speech of the President of Russian Federation V.V. Putin on the expanded meeting of the State council (2008). - Moscow: Publishing-house "Europe".

Aliev V.G. (2003). The theory of organization: Text-book for higher educational institutions of the Ministry of Education and Science of the Russian Federation (2nd ed., revised). Moscow: "Economy".

Efimov V. (2007) Subject and method of interpretative institutional economy. Issues of economy. (8), 59.

Emerson G. (1992) Twelve principles of productivity. (pp. 216) Transl. from Engl. / Scient. ed. V.S. Kardash. (2nd ed). Moscow: Economy.

Eremenko M.I. (2007). The Development of key competences of senior pupils (2nd ed. revised) (pp 112.). Moscow: Globus, Volgograd: Panorama.

Khairullina V.G. (2002). The theory of the market and reality / Formation of socially oriented market economy. Part one. Collection of works of post-graduates and doctoral candidate of the RAS Institute of Economics. Scientific editor - doctor of economic sciences, academician of RAFA Arkhipov A.I. Moscow: RAS Institute of Economics.

Khairullina V.G. (2007). Creative component of labour as imperative of the modern culture / Scien. ed. of the doctor of philos. S., professor V.D. Didenko: monograph. Moscow: Soc.-humanit. "Znania".

Kuzminov Ya., Radaev V., Yakovlev A., Yasin E. (2005) Institutes: from borrowing to growing (experience of the Russian reforms and possibilities of cultivation of institutional changes). Issues of economy. (5), 7 .

Lopukhov A.M. (2012). Dictionary of the terms and notions on the social science (6th edn) - Moscow: Airis-press.

O'Shonessey J. (1979). Principles of company management organization (pp. 9). Moscow: Progress.

Raizberg B.A., Losovskii L.Sh., Starodubtseva E.B. (2007). Modern economic dictionary (pp. 495), (5th ed., revised). Moscow: INFRA-M. Ushakov D.N. (2008). Big explanatory dictionary of modern Russian language.Chelyabinsk: Publ.-house "Bukolika".

Volkov Yu.G. (2005). Regional policy and ideology in the modern Russia. Rostov-on-Don. 